\title{
Zinc ion implantation-deposition technique improves the osteoblast biocompatibility of titanium surfaces
}

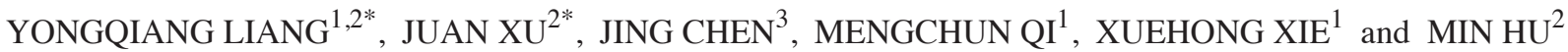 \\ ${ }^{1}$ College of Stomatology, Hebei United University, Tangshan, Hebei 063000; ${ }^{2}$ Department of Stomatology, \\ Chinese People's Liberation Army General Hospital, Beijing 100853; ${ }^{3}$ College of Life Sciences, \\ Hebei United University, Tangshan, Hebei 063000, P.R. China
}

Received February 13, 2014; Accepted January 9, 2015

DOI: $10.3892 / \mathrm{mmr} .2015 .3311$

\begin{abstract}
The plasma immersion ion implantation and deposition (PIIID) technique was used to implant zinc (Zn) ions into smooth surfaces of pure titanium (Ti) disks for investigation of tooth implant surface modification. The aim of the present study was to evaluate the surface structure and chemical composition of a modified Ti surface following $\mathrm{Zn}$ ion implantation and deposition and to examine the effect of such modification on osteoblast biocompatibility. Using the PIIID technique, $\mathrm{Zn}$ ions were deposited onto the smooth surface of pure Ti disks. The physical structure and chemical composition of the modified surface layers were characterized by scanning electron microscopy (SEM) and X-ray photoelectron spectroscopy (XPS), respectively. In vitro culture assays using the MG-63 bone cell line were performed to determine the effects of $\mathrm{Zn}$-modified Ti surfaces following PIIID on cellular function. Acridine orange staining was used to detect cell attachment to the surfaces and cell cycle analysis was performed using flow cytometry. SEM revealed a rough 'honeycomb' structure on the $\mathrm{Zn}$-modified $\mathrm{Ti}$ surfaces following PIIID processing and XPS data indicated that $\mathrm{Zn}$ and oxygen concentrations in the modified Ti surfaces increased with PIIID processing time. SEM also revealed significantly greater MG-63 cell growth on Zn-modified Ti surfaces than on pure Ti surfaces $(\mathrm{P}<0.05)$. Flow cytometric analysis revealed increasing percentages of MG-63 cells in $\mathrm{S}$ phase with increasing $\mathrm{Zn}$ implantation and deposition, suggesting that MG-63 apoptosis was inhibited and MG-63 proliferation was promoted on Zn-PIIID-Ti surfaces. The present results suggest that modification with Zn-PIIID may
\end{abstract}

Correspondence to: Professor $\mathrm{Min} \mathrm{Hu}$, Department of Stomatology, Chinese People's Liberation Army General Hospital, 28 Fuxing Road, Haidian, Beijing 100853, P.R. China

E-mail: humin301@gmail.com

*Contributed equally

Key words: zinc implantation-deposition, titanium surface modification, MG-63 cells, biocompatibility be used to improve the osteoblast biocompatibility of $\mathrm{Ti}$ implant surfaces.

\section{Introduction}

In previous years, implanted prosthodontic dentures have been applied as an effective way to repair either defective or absent dentition. The surface characteristics and morphology of implanted dentures affect the cell survival, adhesion, proliferation and differentiation of dental tissues on denture surfaces (1). Biologically inert titanium (Ti) is widely used in dental implants due to the direct contact between the implant material and the bone $(1,2)$. However, as a bioinert material, Ti cannot be biologically integrated with bone tissue (3). One approach to improve integration has been to roughen endosseous areas of dental implants in order to increase the total surface area available for osseous apposition. Surface roughness has been demonstrated to alter osteoblast attachment, proliferation, differentiation and extracellular matrix (ECM) production (4).

Another limitation of Ti implants is the short delay between implantation and when they are able to impart bactericidal capabilities, which may lead to the formation of dental plaques surrounding implanted dentures (5). Several strategies have been developed to overcome this surface-associated limitation of Ti implants (6-10), including surface modification by plasma immersion ion implantation and deposition (PIIID) (11-13). PIIID generates surface layers that can integrate with specific substrates and this technique has been used to incorporate zinc ( $\mathrm{Zn}$ ) into the surfaces of Ti implants (14). $\mathrm{Zn}$ is a necessary element for cellular activities and is specifically important in the development and maintenance of bone structures (15).

In the current study, a PIIID technique was used to implant $\mathrm{Zn}$ ions onto the smooth surfaces of pure Ti disks. The physical structure and chemical composition of the modified Zn-PIIID-Ti surfaces were evaluated by scanning electron microscopy (SEM) and X-ray photoelectron spectroscopy (XPS), respectively and then the biocompatibility of the Zn-PIIID-Ti surfaces with regard to osteoblast function in vitro was examined.

\section{Materials and methods}

Preparation and surface characterization of Ti disks. Pure Ti (grade 4) disks, $10 \mathrm{~mm}$ in diameter and $1 \mathrm{~mm}$ thick were 
polished on one side to a mirror-like finish and then sequentially subjected to ultrasonication in acetone, absolute alcohol and deionized water. The clean disks were then air-dried and stored in a desiccator. PIIID to implant and deposit $\mathrm{Zn}$ ions was performed at the State Key Laboratory of Advanced Welding Production Technology of the Harbin Institute of Technology (Harbin, China) using the following parameters: Pulse voltage (V) of $20 \mathrm{kv}$; pulse width ( $\tau /$ ) of $300 \mu \mathrm{s}$; Zn-ion pulsed cathodic arc width of $300 \mu \mathrm{s}$ and working pressure $(\mathrm{P})$ of $1 \times 10^{-1} \mathrm{~Pa}$. The source of the $\mathrm{Zn}$ ions was a pulsed cathodic arc. Ti disks were prepared with four different implantation times (T) of $20 \mathrm{~min}$ (Zn-Ti-20 min group), $40 \mathrm{~min}$ (Zn-Ti-40 min group), $60 \mathrm{~min}$ (Zn-Ti-60 min group) and $80 \mathrm{~min}$ (Zn-Ti-80 min group). Commercially pure Ti (cp-Ti) disks without $\mathrm{Zn}$ implantation were used in the control group.

The physical structure of modified Ti disks was observed by SEM (Hitachi S-520; Hitachi, Ltd., Tokyo, Japan) and their chemical composition was characterized by XPS using $300 \mathrm{~W}$ Al $\mathrm{K} \alpha$ radiation and an ESCALab 220i-XL electron spectrometer (VG Scientific, Ltd., East Grinstead, UK). Binding energies were referenced to the $\mathrm{C} 1 \mathrm{~s}$ line at $284.8 \mathrm{eV}$ from trace carbon and the base pressure was $3 \times 10^{-9}$ mbar.

Cell culture. MG-63 human osteosarcoma cells (purchased from the Cancer Institute and Hospital, Chinese Academy of Medical Sciences, Beijing, China) were grown in minimum essential medium with $10 \%$ fetal calf serum (HyClone Laboratories, Inc., Logan, UT, USA), $100 \mathrm{IU} / \mathrm{ml}$ penicillin, $100 \mathrm{IU} / \mathrm{ml}$ streptomycin (North China Pharmaceutical Group Corporation, Shijiazhuang, China) and $2 \mathrm{mM}$ L-glutamine in a humidified atmosphere of $5 \% \mathrm{CO}_{2}$ at $37^{\circ} \mathrm{C}$. Cells were seeded onto surfaces of Zn-modified Ti disks in the Zn-Ti-20, -40, -60 and -80 min groups as well as control disks in 24-well plates at a seeding concentration of $2 \times 10^{4}$ cells $/ \mathrm{ml}$.

SEM observation of cell attachment. The morphology of attached cells was observed by SEM (Hitachi S-520; Hitachi, Ltd.). Following culture for $48 \mathrm{~h}$, the $\mathrm{Zn}$-modified and control Ti disks with attached cells were washed with phosphate-buffered saline (PBS) and the cells were fixed overnight in $2.5 \%$ glutaraldehyde. Following fixation, the samples were sequentially dehydrated (10 min each) in increasing concentrations of ethanol (20, 50, 70, 90 and 100\%). Following dehydration, they were immersed in isoamyl acetate (a critical point drying fluid) for $1.5 \mathrm{~min}$ and finally sputter-coated with a thin layer of gold/palladium for viewing by SEM.

Quantification of cell attachment and proliferation. Cell attachment to the Zn-modified and control Ti disks was quantified using acridine orange (AO) staining. Following a specific incubation time $(6,24$ or $48 \mathrm{~h})$, samples were fixed in $95 \%$ ethanol and stained with $4 \times 10^{4} \mathrm{mg} / \mathrm{ml} \mathrm{AO}$ for $1 \mathrm{~min}$. Following rinsing with PBS, the samples were examined under a fluorescence microscope (FV1000; Olympus, Tokyo, Japan) and the attached cells were counted in randomly selected $2 \mathrm{~mm}^{2}$ areas.

Flow cytometry for cell cycle analysis. After 48 h, MG-63 cells were collected and prepared for flow cytometry (FACSCalibur, Becton Dickinson Immunocytometry Systems, San Jose, CA,
USA). A total of 10,000 cells were counted per sample and the fractions of cells in the G1, S and G2 phases of the cell cycle were determined. This experiment was performed in triplicate.

Statistical analysis. Data are expressed as the mean \pm standard deviation. Statistical analyses were performed using SPSS 12.0 software (SSPS, Inc., Chicago, IL, USA). One-way analysis of variance was conducted to assess differences among all quantitative indices. $\mathrm{P}<0.05$ was considered to indicate a statistically significant difference.

\section{Results}

Structure and chemical composition of pure and Zn-modified Ti surfaces. SEM images of the unmodified cp-Ti surfaces revealed tiny fissures and fuzzy grain edges with smooth shapes (Fig. 1). By contrast, multiple homogeneously and randomly distributed granular masses were apparent on the Zn-PIIID-Ti surfaces with increasing $\mathrm{Zn}$ exposure time. The $\mathrm{Zn}$ appeared to have penetrated into the base material and deposited onto the surface. For longer implantation and deposition times, the interstices among the distributed granular masses increased. The size and shape of the masses were also increasingly more homogeneous and the edges of the grains became much sharper, but no significant differences were observed in the number of minor fissures among the samples prepared with different exposure times $(\mathrm{P}>0.05)$. SEM images revealed that the Ti surfaces exhibited a rough 'honeycomb' structure in which the diameter was $60-100 \mathrm{~nm}$ with PIIID processing. The 'honeycomb' structure deepened with increasing processing time and surfaces in the $\mathrm{Zn}$-Ti-80 min group demonstrated a $200 \mathrm{~nm}$ deep structure with grade 9 smoothness and $0.4 \mu \mathrm{m}$ roughness (Fig. 1F).

The XPS results revealed alterations in the surface layer chemical composition upon Zn-PIIID (Fig. 2). The O1s peak relative intensity significantly decreased following PIIID. An additional peak corresponding to $\mathrm{Zn}$-containing materials was also observed, although its intensity was extremely weak. XPS analysis also was used to obtain relative atomic concentrations of carbon, $\mathrm{Ti}$ and $\mathrm{Zn}$ on the surface of each group (Table I). In the $\mathrm{Zn}-\mathrm{Ti}-20,-40,-60$ and -80 min groups, the percentages of $\mathrm{Zn}$ were $1.04 \pm 0.08,1.32 \pm 0.06,1.35 \pm 0.04$ and $2.14 \pm 0.06$, respectively.

MG-63 morphological alterations on pure and Zn-modified Ti surfaces. As shown in Fig. 3A, MG-63 cells typically have irregular polygon shapes, where the ratio of the macro axis to the minor axis is usually greater than those of other cells growing in the culture flask. SEM analysis revealed that the in vitro morphology of MG-63 cells was altered on Zn-PIIID-Ti surfaces (Fig. 3B). Compared with the predominately round cells observed on the cp-Ti disks (Fig. 3C), cells grown on the Zn-PIIID-Ti disks exhibited a relatively improved spreading and flattening, with an increased cell to substrate contact ratio (Fig. 3D). Increased $\mathrm{Zn}$ implantation resulted in a greater density of attached cells. The cells secreted considerable quantities of ECM protein that covered the granular surface (Fig. 3E) and appeared to be actively proliferating and differentiating (Fig. 3F). Cells on the Zn-PIIID-Ti surfaces also had extensive networks of cytoplasmic processes that extended to 
Table I. X-ray photoelectron spectroscopy elemental percentages for Zinc-plasma immersion ion implantation and deposition on titanium surfaces.

\begin{tabular}{lccccc}
\hline Element & $\mathrm{cp}-\mathrm{Ti}$ & Zn-Ti-20 min & Zn-Ti-40 min & Zn-Ti-60 min & Zn-Ti-80 min \\
\hline $\mathrm{Ti}$ & $62.76 \pm 3.24$ & $65.44 \pm 3.98$ & $64.61 \pm 3.55$ & $61.61 \pm 3.61$ & $57.51 \pm 3.47$ \\
$\mathrm{O}$ & $37.24 \pm 1.26$ & $33.52 \pm 1.33$ & $34.08 \pm 1.19$ & $37.04 \pm 1.38$ & $40.35 \pm 1.41$ \\
$\mathrm{Zn}$ & 0.00 & $1.04 \pm 0.08^{\mathrm{a}}$ & $1.32 \pm 0.06^{\mathrm{a}, \mathrm{b}}$ & $1.35 \pm 0.04^{\mathrm{a}, \mathrm{b}}$ & $2.14 \pm 0.06^{\mathrm{a}, \mathrm{b}, \mathrm{c}}$ \\
\hline
\end{tabular}

${ }^{\mathrm{a}} \mathrm{P}<0.01$, compared with the cp-Ti group; ${ }^{\mathrm{b}} \mathrm{P}<0.05$, compared with the $\mathrm{Zn}-\mathrm{Ti}-20$ min group; ${ }^{\mathrm{c}} \mathrm{P}<0.05$, compared with the $\mathrm{Zn}-\mathrm{Ti}-40 \mathrm{~min}$ and $\mathrm{Zn}-\mathrm{Ti}-60 \mathrm{~min}$ groups. TI, titanium; Zn, zinc. The results are presented as the mean \pm standard deviation.
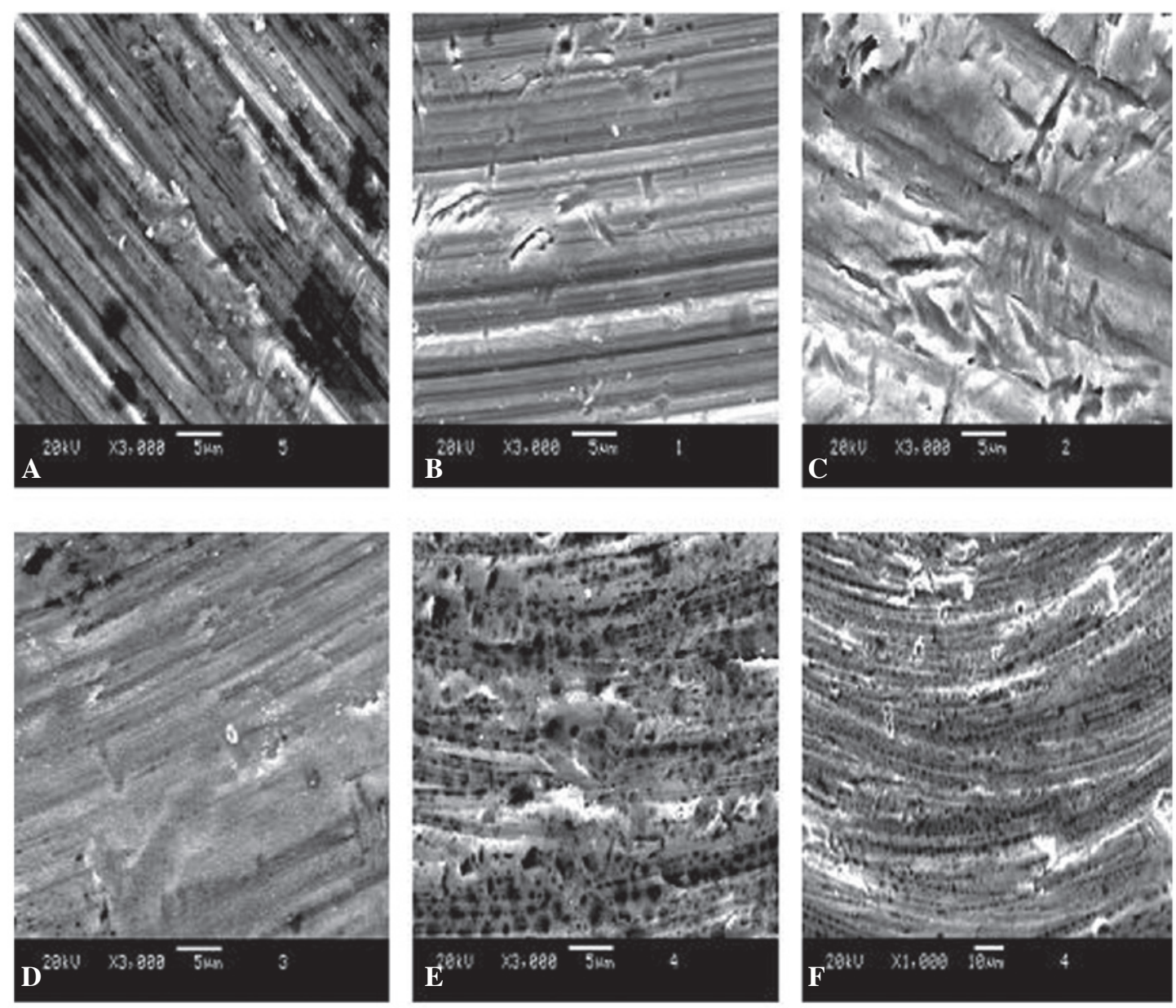

Figure 1. Scanning electron microscope images of unmodified and Zn-modified Ti surfaces. (A) Commercially pure-Ti, (B) Zn-Ti-20 min, (C) Zn-Ti-40 min, (D) Zn-Ti-60 min, (E) Zn-Ti-80 min and (F) Zn-Ti-80 min surfaces. (A-E) Magnification x3,000, scale bar=5 $\mu \mathrm{m}$; (F) magnification x1,000, scale bar=10 $\mu \mathrm{m}$. TI, titanium; Zn, zinc.

the underlying substrate and connected to neighboring cells, whereas cells on the cp-Ti surfaces had far fewer and shorter fibrillar extensions.

Cell proliferation on pure and Zn-modified Ti surfaces. The initial attachment of cells is crucial to subsequent cell spreading, proliferation and differentiation on substrates. As shown in Fig. 4 by fluorescence microscopy, the number of attached and proliferating MG-63 cells increased with culture time for all samples. At $6 \mathrm{~h}$ after cell seeding, there were no significant differences identified in cell proliferation among the five samples ( $P>0.05)$. However, after $24 \mathrm{~h}$, a higher density of cells was present on the Zn-PIIID-Ti surfaces compared with that on the cp-Ti surface $(\mathrm{P}<0.05)$. This trend became more pronounced for higher levels of $\mathrm{Zn}$ ion implantation and deposition, whereas no significant difference in the quantified numbers of cells was noted between the Zn-Ti-60 min and Zn-Ti-80 min groups ( $>0.05$; Fig. 5).

MG-63 cell cycle distribution on pure and Zn-modified Ti surfaces. After $48 \mathrm{~h}$ in culture, flow cytometric analysis revealed that the percentage of cells in S phase was $28.62 \%$ 


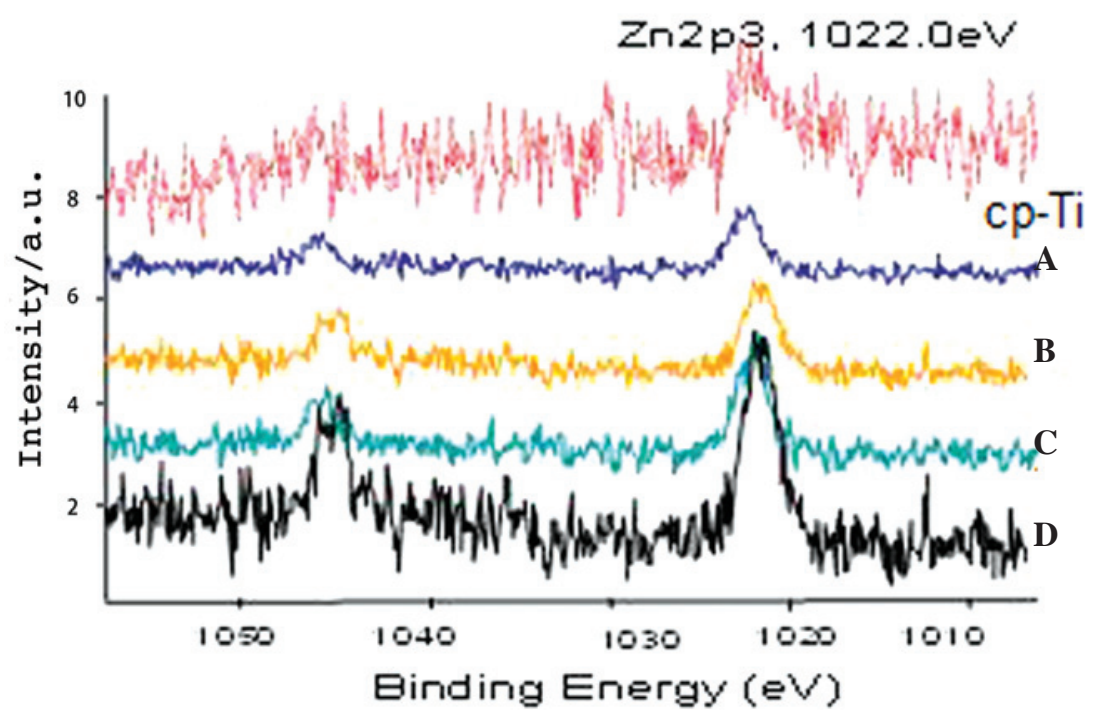

Figure 2. X-ray photoelectron spectra of unmodified (top) and Zn-modified Ti surfaces. (A) Zn-Ti-20 min, (B) Zn-Ti-40 min, (C) Zn-Ti-60 min and (D) Zn-Ti-80 min. TI, titanium; Zn, zinc.
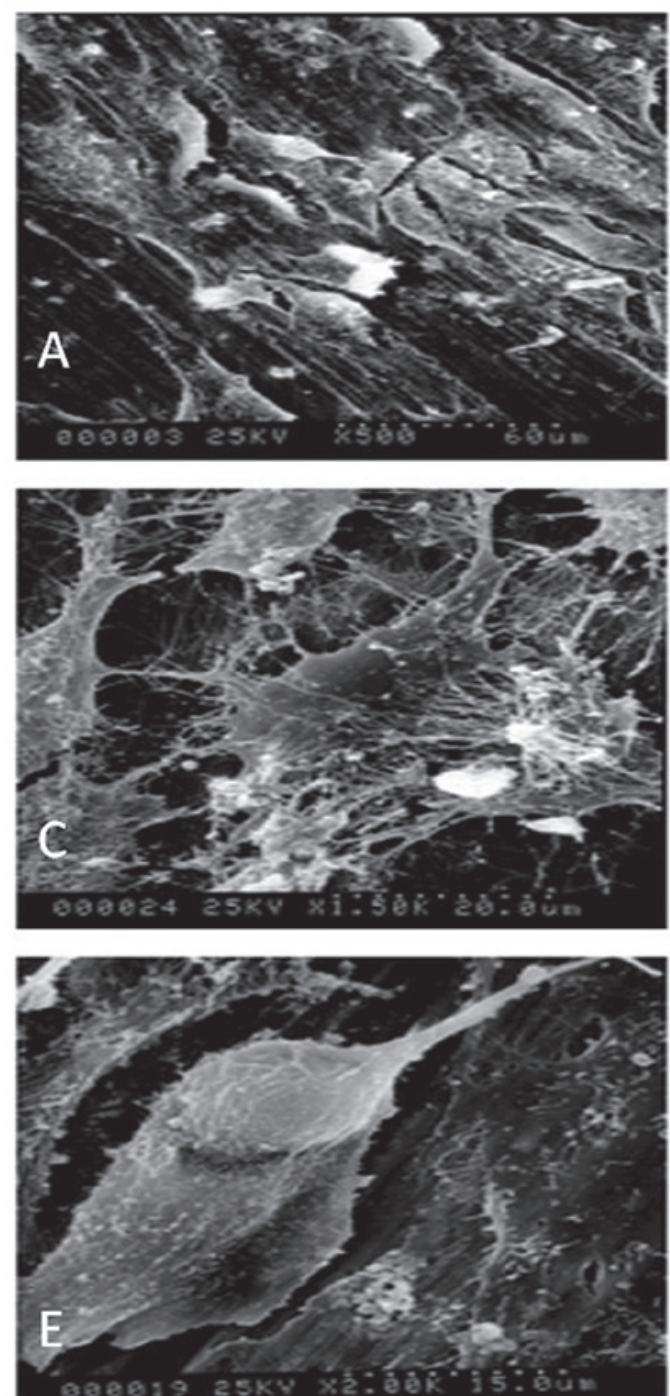
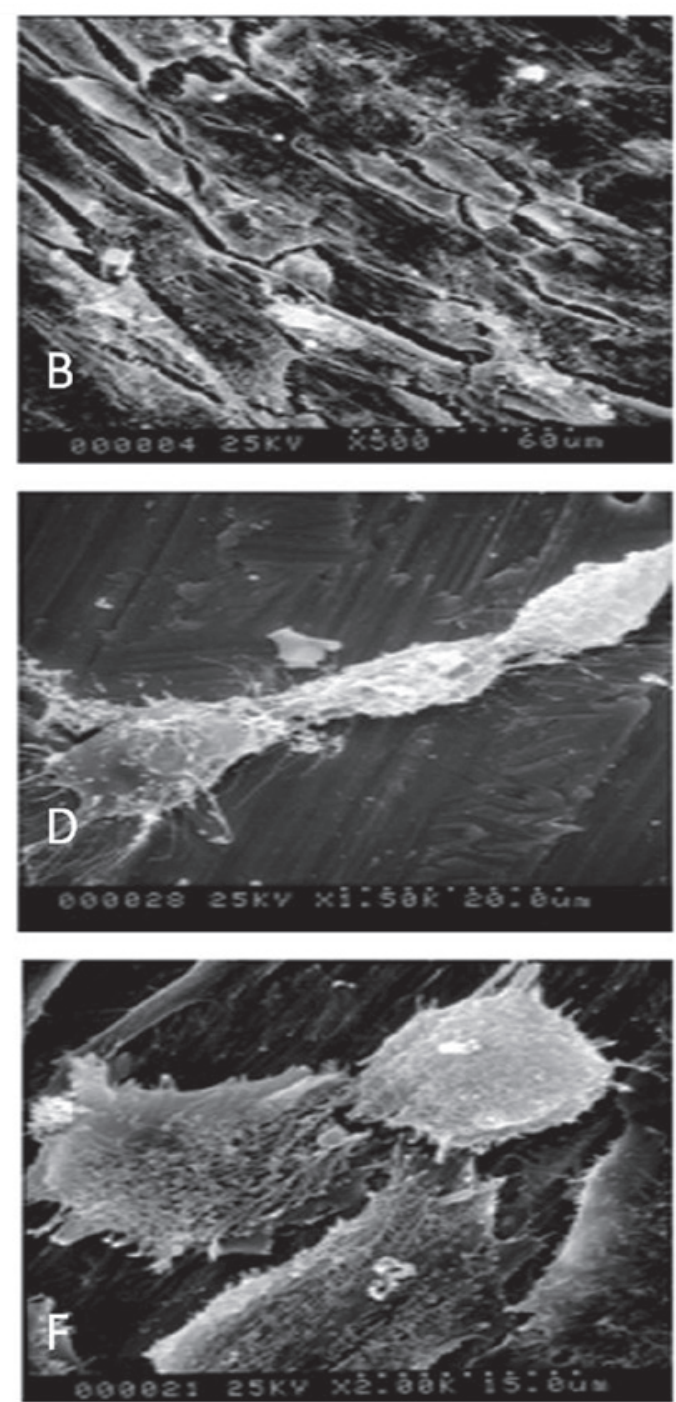

Figure 3. Scanning electron microscope images demonstrating the morphology of MG-63 cells on unmodified and Zn-modified Ti surfaces. (A and C) MG-63 cells on cp-Ti; (B and D-F) MG-63 cells on Zn-Ti-20 min surfaces. (C) MG-63 cells were primarily rounded on unmodified Ti surfaces, whereas on the (D) Zn-modified Ti surfaces, cells assumed fusiform shapes with well-spread pseudopodia and extensive networks of cytoplasmic processes. (D) Secreted extracellular matrix was visible covering the substrate granules and (E) cells undergoing division were observed. (A and B) Magnification, x500. (C and D) Magnification, x1,500. (E and F) Magnification, x2,000. Cp, commercially pure; TI, titanium; Zn, zinc. 

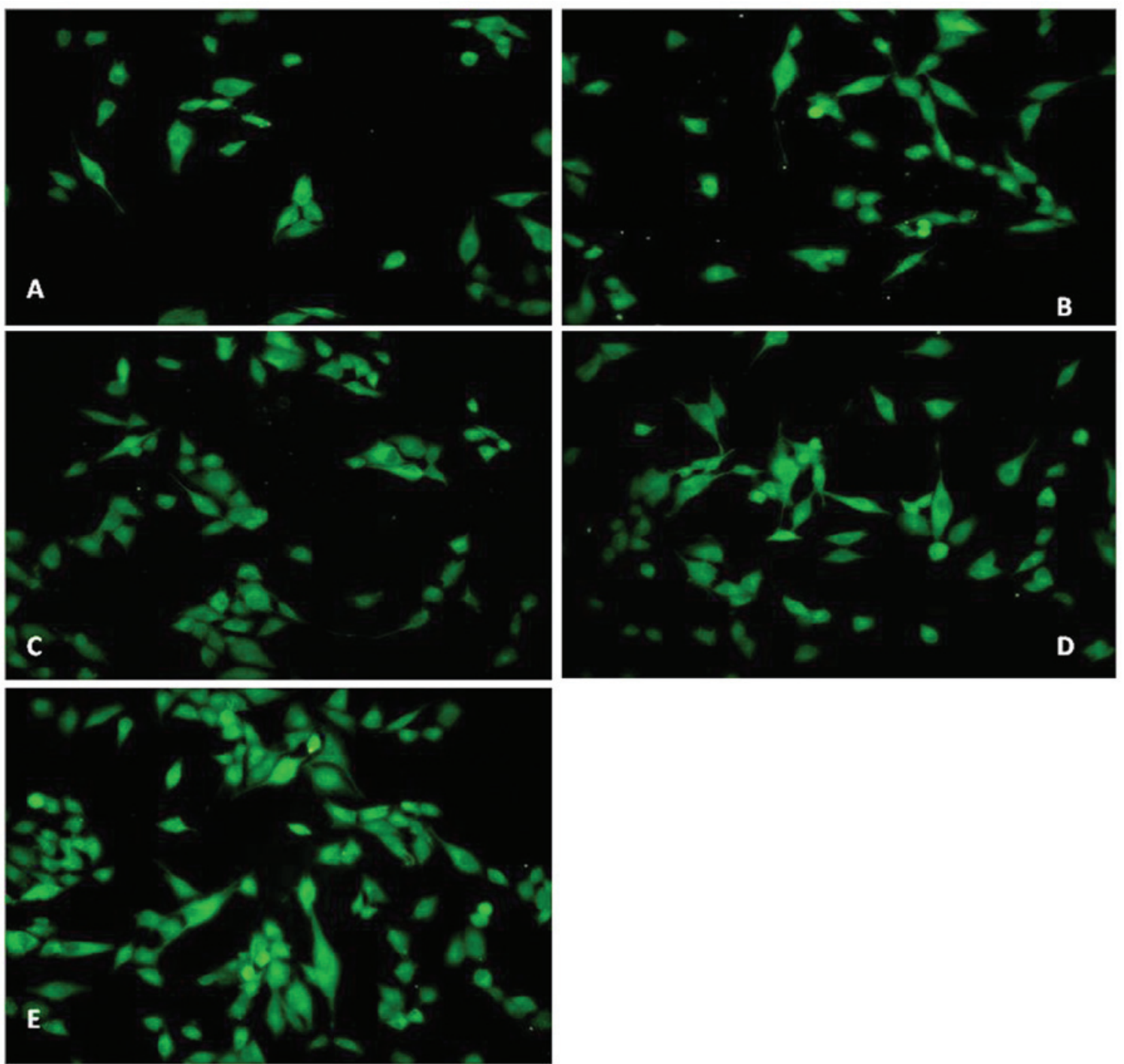

Figure 4. Fluorescence microscopy images of MG-63 cell proliferation on unmodified and Zn-modified Ti surfaces. Acridine orange-stained MG-63 cells on (A) cp-Ti, (B) Zn-Ti-20 min, (C) Zn-Ti-40 min, (D) Zn-Ti-60 min and (E) Zn-Ti-80 min surfaces after $24 \mathrm{~h}$ in culture. Cp, commercially pure; Ti, titanium; Zn, zinc.

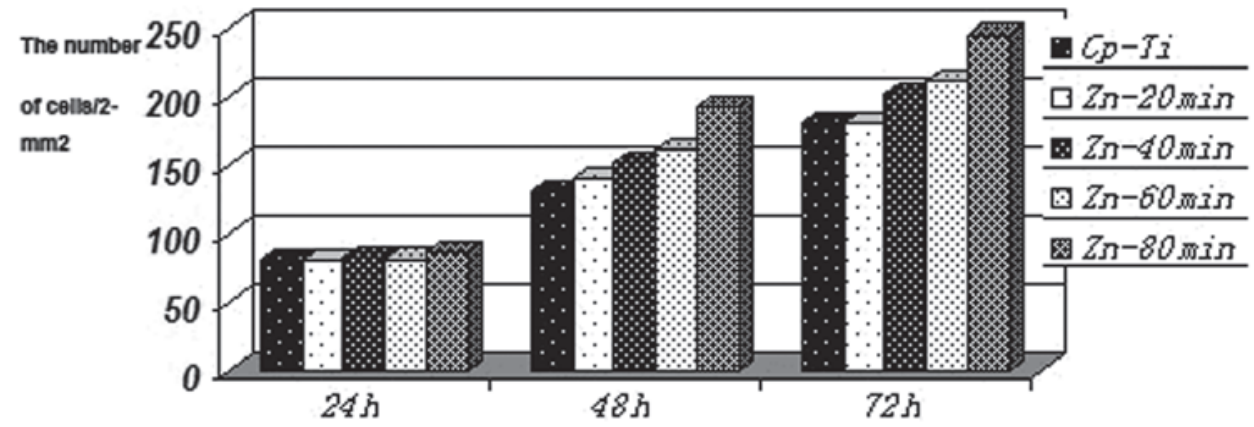

Figure 5. Number of MG-63 cells (per $2 \mathrm{~mm}^{2}$ area) observed on unmodified cp-Ti and Zn-modified Ti surfaces with increasing culture time (n=12). Cp, commercially pure; TI, titanium; $\mathrm{Zn}$, zinc.

in the cp-Ti group (Fig. 6A), 30.1\% in the Zn-Ti-20 min group (Fig. 6B), $31.9 \%$ in the Zn-Ti-40 min group (Fig. 6C), $34.2 \%$ in the $\mathrm{Zn}-\mathrm{Ti}-60$ min group (Fig. 6D) and $36.3 \%$ in the Zn-Ti-80 min group (Fig. 6E). These percentages for each of the five groups were significantly different from each other
$(\mathrm{P}<0.01)$ within this gradual increase in the $\mathrm{S}$ phase from the $\mathrm{Zn}-\mathrm{Ti}-20$ min group to the $\mathrm{Zn}-\mathrm{Ti}-80$ min group. These results demonstrated that the modified Zn-PIIID-Ti surfaces may inhibit MG-63 cell apoptosis as well as promote proliferation. 
A

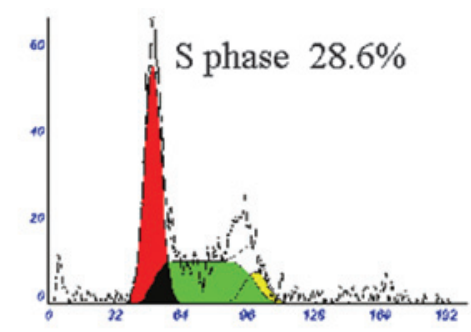

B

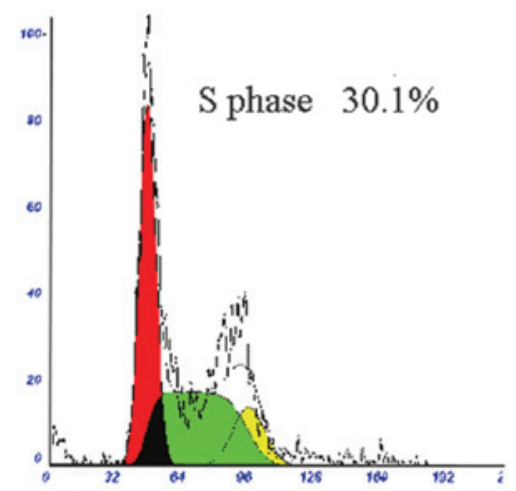

D

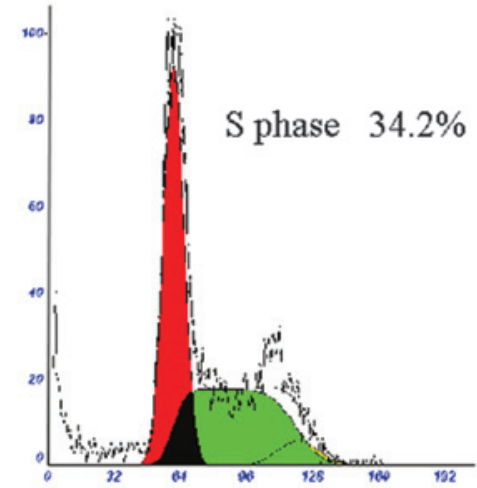

C

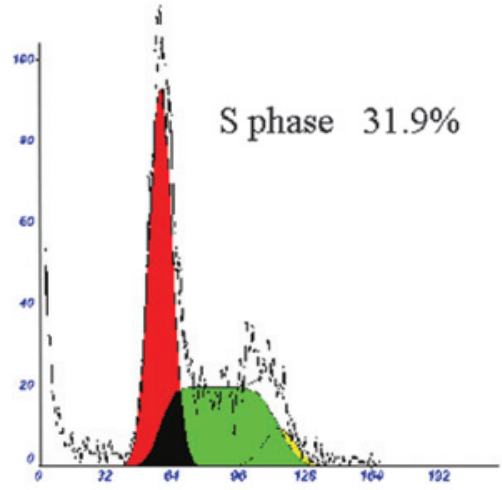

E

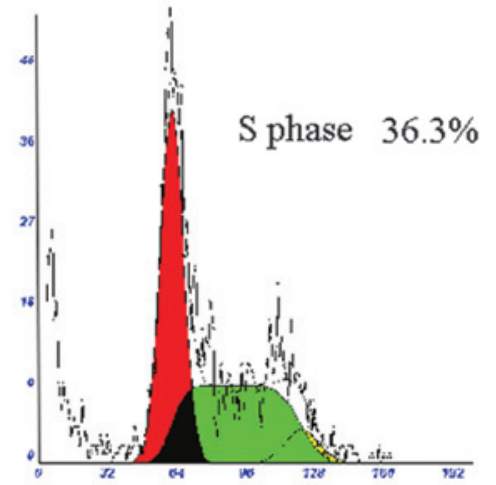

Figure 6. Cell cycle analysis of MG-63 cells on (A) commercially pure-Ti, (B) Zn-Ti-20 min, (C) Zn-Ti-40 min, (D) Zn-Ti-60 min and (E) Zn-Ti-80 min surfaces after $48 \mathrm{~h}$ in culture. Data represent numbers of cells per $2 \mathrm{~mm}^{2}$ area. $\mathrm{Zn}$, zinc; Ti, titanium.

\section{Discussion}

Previous studies have reported that increased surface roughness of Ti implants improves the rate of osseointegration and biomechanical fixation (16-18). Surface roughness in the nanometer range is important in the absorption of proteins and adhesion of osteoblastic cells and thus affects the rate of osseointegration (19). However, surface roughness at this scale is difficult to achieve using chemical treatments. In addition, the optimal surface nanotopography for selective adsorption of proteins that enable adhesion of osteoblastic cells and rapid bone apposition remains to be elucidated. Therefore, other roughening methods with more predictable outcomes are required.

PIIID overcomes the limitations of regular ion beam implantation and is suitable for processing samples with complex shapes (20). Following PIIID processing, the anti-corrosion, anti-abrasion and anti-fatigue properties of materials are significantly improved and therefore, it has gained attention worldwide and is now used in several biomedical applications (11-13). In the present study, PIIID was used to implant and deposit $\mathrm{Zn}$ ions within and onto the smooth surface of cp-Ti.

According to XPS analysis, with increasing $\mathrm{Zn}$ ion implantation and deposition time, carbon, Ti and $\mathrm{Zn}$ signals increased on the Zn-PIIID-Ti surfaces, whereas oxygen signals decreased. The significant $\mathrm{Zn}$ content on the surface reached its maximum with the $80 \mathrm{~min}$ deposition time. Following implantation and deposition, the surfaces contained $\mathrm{ZnO}$ and $\mathrm{TiO}_{2}$. SEM imaging revealed that following Zn-PIIID, dispersed lumps had formed on the originally smooth $\mathrm{Ti}$ surface and this may explain why certain $\mathrm{Zn}$ ions were implanted within the substrate matrix in the form of interstitial atoms, while other $\mathrm{Zn}$ ions deposited directly onto the $\mathrm{Ti}$ surface. Notably, the physical structure of the Zn-Ti-80 min sample surface was the most homogeneous among assessed surfaces, indicating that the size of granular masses became more uniform with increasing PIIID processing time. SEM, in turn revealed that Ti surfaces exhibited a rough 'honeycomb' structure with a diameter range of $60-100 \mathrm{~nm}$ upon PIIID processing. The 'honeycomb' structure continually deepened with increasing PIIID processing time and reached a depth of $200 \mathrm{~nm}$ with grade 9 smoothness and $0.4 \mu \mathrm{m}$ roughness in the Zn-Ti-80 min group. Thus, the present study demonstrated that the PIIID technique for Ti surface modification offers an easy and effective way to increase the roughness of the surfaces of Ti implants and the degree of roughness achieved is more significant, with a deeper nanostructure, than that generated using other methods $(6,21,22)$. 
MG-63 cells were seeded onto pure and Zn-modified Ti surfaces in order to assess the effects of $\mathrm{Zn}$ implantation and deposition on the biocompatibility of the Ti surfaces. SEM images revealed pseudopodia extending from osteoblasts residing on the $\mathrm{Zn}$-modified $\mathrm{Ti}$ surfaces, indicating active cellular metabolism. Cells extended multiple long and slender pseudopodia that inserted between the granules of the Zn-modified Ti surfaces and formed anchoring structures for strong adhesion. The present study also revealed that the density of attached cells on the Zn-modified surfaces was significantly greater than that observed on the unmodified Ti surfaces and the secretion of ECM proteins followed this trend as well, with ECM proteins covering the granules of Zn-modified Ti surfaces. The current findings are in agreement with the electron microscopy images presented in previous studies $(14,23,24)$ of murine bone marrow cells grown on hydroxyapatite-coated cp-Ti surfaces following $2 \mathrm{~h}$ incubation.

Based on the collective results of the present study, it is concluded that Ti substrates modified using Zn PIIID exhibit improved biocompatibility with the MG-63 cell line compared with cp-Ti and thus may be applicable in a wide variety of dental implants. Experiments to determine the in vivo performance of these $\mathrm{Zn}$-modified Ti substrates are underway. Based on the present results demonstrating the biocompatibility of these substrates as well as previous findings that $\mathrm{Zn}$-modified Ti surfaces discourage bacterial adhesion (14), it is expected that $\mathrm{Zn}$-modification of Ti may enhance the success rate of dental implants.

\section{Acknowledgements}

This study was supported by the Beijing Natural Science Foundation (grant no. 7112124) and the Natural Science Foundation of Hebei Province (grant no. H2013209040).

\section{References}

1. Rudy RJ, Levi PA, Bonacci FJ, Weisgold AS and Engler-Hamm D: Intraosseous anchorage of dental prostheses: an early 20th century contribution. Compend Contin Educ Dent 29: 220-222, 2008.

2. Elias CN, Oshida Y, Lima JH and Muller CA: Relationship between surface properties (roughness, wettability and morphology) of titanium and dental implant removal torque. J Mech Behav Biomed Mater 1: 234-242, 2008.

3. Condie R, Bose S and Bandyopadhyay A: Bone cell-materials interaction on $\mathrm{Si}$ microchannels with bioinert coatings. Acta Biomater 3: 523-530, 2007.

4. Hara T, Matsuoka K, Matsuzaka K, Yoshinari M and Inoue T: Effect of surface roughness of titanium dental implant placed under periosteum on gene expression of bone morphogenic markers in rat. Bull Tokyo Dent Coll 53: 45-50, 2012.

5. Oga M, Arizono T and Sugioka Y: Bacterial adherence to bioinert and bioactive materials studied in vitro. Acta Orthop Scand 64: 273-276, 1993.
6. Li F and Zhu L: Effect of surfactant-induced cell surface modifications on electron transport system and catechol 1,2-dioxygenase activities and phenanthrene biodegradation by Citrobacter sp. SA01. Bioresour Technol 123: 42-48, 2012.

7. Nieciecka D, Nawara K, Kijewska K, et al: Solid-core and hollow magnetic nanostructures: Synthesis, surface modifications and biological applications. Bioelectrochemistry 93: 2-14, 2013.

8. Yamaguchi $\mathrm{H}$, Ino $\mathrm{S}$, Hamano $\mathrm{N}$, Okada $\mathrm{S}$ and Teranaka $\mathrm{T}$ : Examination of bond strength and mechanical properties of Y-TZP zirconia ceramics with different surface modifications. Dent Mater J 31: 472-480, 2012.

9. Iwai Y, Matsuda Y, Nakatsuka M, Mikami Y and Kumabe S: A preliminary study of the dental implant therapy - initial osteogenesis of human mesenchymal stem (HMS0014) cells on titanium discs with different surface modifications. Okajimas Folia Anat Jpn 88: 133-140, 2012.

10. Qin Z, Huang Y, Liao Q, Zhang Z and Zhang Y: Effect of surface modifications on $\mathrm{ZnO}$ nanorod arrays electrode for dye-sensitized solar cells. J Nanosci Nanotechnol 12: 463-468, 2012.

11. Wang L, Huang L, Xie Z, Wang X and Tang B: Fourth-generation plasma immersion ion implantation and deposition facility for hybrid surface modification layer fabrication. Rev Sci Instrum 79: 023306, 2008

12. Kwok SC, Yang P, Wang J, Liu X and Chu PK: Hemocompatibility of nitrogen-doped, hydrogen-free diamond-like carbon prepared by nitrogen plasma immersion ion implantation-deposition. J Biomed Mater Res A 70: 107-114, 2004.

13. Yang P, Huang N, Leng YX, et al: Activation of platelets adhered on amorphous hydrogenated carbon $(\mathrm{a}-\mathrm{C}: \mathrm{H})$ films synthesized by plasma immersion ion implantation-deposition (PIII-D). Biomaterials 24: 2821-2829, 2003.

14. Xua JA, Ding G, Li JL, et al: Zinc-ion implanted and deposited titanium surfaces reduce adhesion of Streptococccus mutans. Appl Surf Sci 256: 7540-7544, 2010.

15. Anna K, Nina P, Yuri K, et al: Coating zinc oxide submicron crystals on poly(methyl methacrylate) chips and spheres via ultrasound irradiation. Ultrason Sonochem 15: 839-845, 2008.

16. Le Guéhennec L, Soueidan A, Layrolle P and Amouriq Y: Surface treatments of titanium dental implants for rapid osseointegration. Dent Mater 23: 844-854, 2007.

17. Chung SH, Kim HK, Shon WJ and Park YS: Peri-implant bone formations around $(\mathrm{Ti}, \mathrm{Zr}) \mathrm{O}(2)$-coated zirconia implants with different surface roughness. J Clin Peridontol 40: 404-411, 2013.

18. Sul YT: Electrochemical growth behavior, surface properties, and enhanced in vivo bone response of $\mathrm{TiO}_{2}$ nanotubes on microstructured surfaces of blasted, screw-shaped titanium implants. Int J Nanomedicine 5: 87-100, 2010.

19. Triplett RG, Frohberg U, Sykaras N and Woody RD: Implant materials, design and surface topographies: their influence on osseointegration of dental implants. J Long Term Eff Med Implants 13: 485-501, 2003.

20. Sosa NE, Chen C, Liu J, et al: Nanoscale structure, composition and charge transport analysis of transparent conducting oxide nanowires written by focused ion beam implantation. J Am Chem Soc 132: 7347-7354, 2010.

21. Minagar S, Berndt CC, Wang J, Ivanova E and Wen C: A review of the application of anodization for the fabrication of nanotubes on metal implant surfaces. Acta Biomater 8: 2875-2888, 2012.

22. Saksø M, Jakobsen SS, Saks $\varnothing$ H, et al: Acid etching and plasma sterilization fail to improve osseointegration of grit blasted titanium implants. Open Orthop J 6: 376-382, 2012.

23. Hempel U, Hefti T, Dieter P and Schlottig F: Response of human bone marrow stromal cells, MG-63 and SaOS-2 to titanium-based dental implant surfaces with different topography and surface energy. Clin Oral Implants Res 24: 174-182, 2013.

24. Cosar M, Ozer AF, Iplikcioglu AC, et al: The results of beta-tricalcium phosphate coated hydroxyapatite (beta-TCP/HA) grafts for interbody fusion after anterior cervical discectomy. J Spinal Disord Tech 21: 436-441, 2008. 